\title{
Genetic And Environmental Factors Involved In The Development Of Oral Malformations Such As Cleft Lip/Palate In Non-Syndromic Patients And Open Bite Malocclusion
}

\author{
M. F. C. Leal, A. Lemos, G. F. Costa, and I. Lopes Cardoso
}

\begin{abstract}
Among the most common malformations observed in the oral cavity are cleft lip/palate and malocclusions, being this last one considered by the World Health Organization, the third public health problem.

Malocclusions include the anterior open bite, a change in the vertical plane, that can be of two types: dental anterior open bite and skeletal anterior open bite. Cleft lip and cleft palate are the most common congenital malformations at birth. These malformations result from a failure in the normal craniofacial development process, which requires the coordination of a complex series of events. From the embryological point of view, the cleft lip/palate is a consequence of the failure of the first superior branchial arch to complete fusion with the frontonasal process during pregnancy.

All these malformations result from the interaction of both genetic and environmental factors. Among the environmental factors involved in the development of malocclusions are deleterious habits, mouth breathing and trauma. Several genes involved in the development of facial bones, muscles and teeth are also responsible for the development of malocclusions. In the same way, clefts development is a multifactorial trait where multiple genes are involved as well as environmental factor like alcohol consumption, tobacco, exposure to pesticides or toxic solvents, in a complex interaction.

All these factors may jeopardize the normal functioning of the stomatognathic system and the consequent quality of life of the patient. The purpose of this study was to review the literature concerning the genetic and environmental aspects involved in the development of these malformations.
\end{abstract}

Index Terms-Cleft lip; Cleft palate; Non-syndromic; Genetic factors; Environment factors; Malocclusion; Open bite

Published on June 05,2020

M. F. C. Leal, Health Sciences Faculty, University Fernando Pessoa, Portugal. (e-mail: fleal@ufp.edu.pt)

A. Lemos, Health Sciences Faculty, University Fernando Pessoa, Portugal. (e-mail: 38841@ufp.edu.pt)

G. F. Costa, Health Sciences Faculty, University Fernando Pessoa, Portugal. (e-mail: 39024@ufp.edu.pt)

I. Lopes Cardoso, Health Sciences Faculty, University Fernando Pessoa, Portugal. (corresponding e-mail: mic@ufp.edu.pt)

\section{INTRODUCTION}

Oral malformations can occur quite frequently, and several independent risk factors have been pointed out as possibly involved in their development.

One of such malformations is cleft lip/palate that has been found to result from multifactorial inheritance, including genetic and environmental factors [1] [2]. Epidemiological and experimental data suggest that environmental risk factors, such as poor nutrition, use of medications, such as phenytoin, smoking and alcohol consumption during pregnancy, may be determinants in the development of cleft lip/palate [3] [4].

Although there has been marked progress in identifying genetic and environmental causes for syndromic cleft lip/palate, the etiology of the most common non-syndromic (isolated) forms remains poorly characterized [3].

The heterogeneity of cleft lip/palate has important implications in understanding the biology of facial development. Several questions concerning how environmental risks interact with genetic factors, and how it will be possible to use such etiological variables to improve the clinical care of patients affected by non-syndromic cleft lip/palate, are in the process of being elucidated [5].

Recently, several genetic and environmental risk factors have been identified for non-syndromic cleft lip/palate. These discoveries allowed to broaden the understanding of developmental biology and created new opportunities for clinical research [6].

In view of the close relationship between environmental and genetic factors in the appearance of cleft lip/palate, the purpose of this literature review was to describe how these factors can lead to the development of cleft lip/palate in nonsyndromic patients. It is of extreme importance that constant research continues to be carried out, in order to highlight characteristics and lifestyles that promote this type of malformation and that causes several inconveniences to patients. In this way, based on new results, it will be possible to promote improvements in the diagnosis of these interrelationships in order to implement effective and safe treatment plans.

In the same way, for centuries, the increasing prevalence of dental malocclusions has been a trend attributed to the interaction of different factors, both genetic and environmental [7]. According to reference [8], dental malocclusion comes from anomalies that appear during the period of childhood and adolescence, in the stage of growth and development, affecting mainly the muscles and the 
maxillary bones, thus causing changes at the aesthetic and functional level. Its occurrence depends on different variables such as genetic factors and the habits established during this period of life.

Open bite is a multifactorial malocclusion resulting from the interaction between the environment and genetics. It is the result of functional etiological factors, including deleterious habits, mouth breathing, trauma, and pathologies [9].

It is possible that the open bite is also influenced by genetic factors, associated with genes that act on the growth and development of teeth, soft tissues, and facial bones [10]. Several studies highlight the genes involved in bone development, such as the CYP19A1 gene, the gene encoding the growth hormone receptor ( $G H R$ gene) and the genes encoding tumor necrosis factor (TNF- $\alpha)$, RANKL/RANK and osteoprotegerin (OPG). The genes that intervene in muscle development and function such as the $M Y O 1 H$ gene, matrix metalloproteinases (MMP), tissue inhibitors of metalloproteinases (TIMPs), genes that encode $\alpha$-actin, and finally those that intervene in morphogenesis and eruption dentistry as the gene encoding the parathyroid hormone receptor (PTHRl gene) [11].

To carry out this bibliographic review, a search was made in the electronic databases PubMed Central and Cochrane Library and Scientific Electronic Library Online (SciELO), using the following keywords: genetic factors, environmental factors, malocclusion, open bite, cleft palate, cleft lip, non-syndromic. Papers in English language, between the years 2000 and 2019 were selected. Articles prior to this period were also chosen for their historical importance and relevance to the study.

\section{NON-SYNDROMIC OROFACIAL CLEFTS}

Non-syndromic orofacial clefts are a heterogeneous group of disorders that affect the structure of the face and oral cavity. They are divided into three general categories: those that affect only the lip (cleft lip); those that affect the lip and palate (cleft lip and cleft palate) and those that affect only the palate (cleft palate). These anomalies can be complete or incomplete and can be found unilaterally and/or bilaterally [5] [12] [13].

Orofacial clefts are the most common congenital malformations at birth [14]. Cleft lip/palate are defects characterized by incomplete closure of the upper lip with an alveolar cleft and/or incomplete closure of the hard palate [5] [13] [15]. The clefts in the midline of the upper lip or the lower lip, rare clefts and oblique facial clefts are not part of the set of cleft lip/palate [3].

The average worldwide incidence of any type of orofacial malformation is 1 per 1000 births, with cleft lip/palate being the predominant malformations [2] [16]. In syndromic forms, cleft lip/palate are associated with other phenotypes, such as heart disease and delayed neuro-psychomotor development, while in non-syndromic forms there are no other associated symptoms [17].

In $70 \%$ of affected individuals, the cleft lip/palate are of the non-syndromic form, which is characterized by incomplete fragmentation between the oral and nasal cavities without other associated anomalies. In most cases, non-syndromic cleft lip/palate are considered to be clinical entities other than clefts where only the palate is affected, as the formation of the primary palate and the central part of the upper lip and nose ( 4 to 7 weeks) occurs before the formation of the palate (between the $8^{\text {th }}$ and $12^{\text {th }}$ weeks) throughout embryonic development [18].

As for ethnicity, the prevalence of cleft lip/palate is more common in Asian and Amerindian populations and less frequent in populations of African origin [17]. According to reference [6], in China, the isolated type of orofacial cleft is the second most common defect present at birth, which makes Asians the population with the highest incidence in the world.

\section{A. Embryological Aspects of Cleft Lip/Palate}

Non-syndromic cleft lip/palate are conditions caused by the combination of genetic and environmental factors. Proper face development requires coordination of a complex series of events that include cell growth, migration, differentiation, and apoptosis [13].

Clefts can arise due to flaws in any of the various stages of embryonic development. According to reference [5], to understand the etiology and elucidate the causes of cleft lip/palate, it is necessary to understand the complex developmental processes that lead to the formation of the upper lip, both at the morphogenetic and molecular level.

The development of the face begins in the $4^{\text {th }}$ week of gestation, when the cells of the neural crest migrate to form the five facial primordia: the frontonasal prominence, the paired mandibular processes, and the paired maxillary processes. These changes occur in different periods, since the embryogenesis of the lip and palate does not occur simultaneously [5]. Between the $4^{\text {th }}$ and $7^{\text {th }}$ week of pregnancy, the medial and lateral nasal processes merge into the maxillary process forming the primary palate, the central part of the upper lip and the nose. Between the $8^{\text {th }}$ and $12^{\text {th }}$ week of intrauterine life, by merging the plates of the secondary palate, the hard palate and the soft palate are formed. When failures in the maxillary and/or palatal processes occur, the individual is affected by lip and/or palate clefts [20].

Historically, cleft lip and cleft lip/palate have been considered variants of the same defect, differing only in severity [12]. Although the primary and secondary palates have different origins of development, cleft lip and cleft lip/palate share a defect in the primary palate, which led to their inclusion in the same group - cleft lip with or without cleft palate (cleft lip/palate) [21] [22]. However, epidemiological [23] and biological data [24] [25] suggest that cleft lip and cleft lip/palate may have different genetic etiologies. Nevertheless, common pathways may be underlying the etiologies of each group, since, occasionally, they are present in patients of the same ethnicity. This event is generally called a mixed cleft and is most seen in syndromic cleft forms [26].

\section{B. Epidemiology and Etiology of Cleft Lip/Palate}

The underlying etiology is complex and multifactorial, with several influences, including genetic, environmental, geographic, racial, and ethnic, as well as socioeconomic status [27]. In general, Asian, and Amerindian populations have the highest reported prevalence rates of births with cleft lip/palate, usually as high as $1 / 500$. Populations of European 
origin have intermediate prevalence rates of around 1/1000, and those of African origin have the lowest prevalence rates (around 1/2500). These observations suggest that the relative contribution of individual susceptibility genes can vary between different populations [3].

Although members of the same family may have cleft lip and cleft palate, the pattern of inheritance does not fit the typical Mendelian genetics [28]. The risk of recurrence of non-syndromic cleft lip with or without cleft palate in siblings and subsequent children of the affected child is approximately 3 to $5 \%$. The frequency of cleft lip with or without cleft palate also differs between sexes and between the sides (left and right) of the face. There is a 2:1 ratio of men to women for cleft lip and approximately a 1:2 ratio of men to women for cleft palate only. There is also a 2:1 ratio of slits from left to right between cases of unilateral cleft lip [3].

Reference [29] carried out a study with the aim of presenting all types of clefts, and their relationship with gender and the side of the body. The study group included 434 patients with facial clefts (218 men and 216 women) aged from 4 weeks to 18 years, who were born in Lódź (Poland) during the years 1981-2015. The results showed $41.7 \%$ of cleft palate, $36 \%$ of cleft lip/palate and $22.3 \%$ of cleft lip. The study showed that isolated cleft palate is more frequent in women than in men, while cleft lip and palate is more frequent in men. In addition, clefts on the left side of the face are more common than on the right side.

\section{Genetic Factors Involved in Cleft Lip/Palate Development}

According to reference [28], more than 350 genes have syndromic and/or non-syndromic associations in humans. Although the genes involved in genetic disorders with oral cleft phenotypes are known, there is still a gap between the detection of these associations and the interpretation of their biological importance.

Although the family association of orofacial clefts has long been observed [30]-[32], formal genetic studies did not begin until reference [21] proposed that genetic factors contribute to cleft lip/palate, after observing an increased frequency of clefts in relatives of a patient with a cleft [21]. Segregation analyses [33] and studies with twins [34] later supported a genetic component for cleft lip/palate, as they have a high rate of family recurrence.

The risk of cleft lip in first degree relatives is estimated at 32 times the risk for individuals without a family history of cleft lip [35]. The 40 to $60 \%$ concordance rate in monozygotic twins is higher than the 3 to $5 \%$ rate in dizygotic twins and suggests a strong genetic etiology [13] [36].

Estimates in various populations show that $20 \%$ of total cases of cleft lip/palate are familiar [20] [37]. In cases with family recurrence, it is assumed that the genetic contribution to the appearance of cleft lip/palate is more prevalent. Consequently, the comparison of the proportion of familial and isolated cases in different geographic regions can point to locations where the factors of predisposition to cleft lip/palate are different [38]-[41].

There is substantial phenotypic diversity in individuals with these birth defects and their families, that go from subclinical phenotypes to associated syndromic characteristics. This reflects that many genes contribute to the etiology of these disorders.

The identification of these genes and loci has been the result of decades of research using multiple genetic approaches. Recently, significant progress has been made due to advances in sequencing and genotyping techniques [2].

A study of reference [39], showed the multi-ethnic association across the genome and identified new loci for the cleft lip/palate. The results allowed to identify new risk loci for these conditions, and new genes involved in craniofacial development have been suggested, confirming the highly heterogeneous etiology of orofacial clefts. Although several genes have been identified as genetic risk factors, the IRF6 gene coding for the interferon regulatory factor 6 , is the best documented genetic risk factor [16] [28] [42].

The IRF6 gene is one of nine members of a family of transcription factors that share a highly conserved DNA binding domain and a less conserved protein binding domain [43]. Reference [44] found that guinea pigs with an IRF6 deficiency have abnormal craniofacial, skin and limb development. Another study suggested that IRF6 acts on the cell cycle, regulating mammary epithelial cell differentiation [45]. Moreover, reference [24] found that the single nucleotide polymorphism (SNP) rs642961 in the IRF6 region that affects the binding site of the transcription factor AP-2 $\alpha$, can directly increase the risk of non-syndromic cleft lip/palate, by altering the transcription of the IRF6 gene. Reference [16] confirmed that the rs642961 polymorphism is significantly associated with an increased risk of nonsyndromic cleft lip/palate.

Non-syndromic orofacial clefts have a complex etiology due to the contribution of genetic and environmental risk factors, as well as the interaction between them. Among the more than 15 loci of susceptibility to non-syndromic orofacial clefts, with considerable statistical and biological support, IRF6 is the gene most validated by most studies. The purpose of the study of reference [42] was to investigate the association of the IRF6 gene polymorphisms with the development of non-syndromic orofacial clefts in a population in the north-eastern Brazil. The SNPs rs2235371, rs642961, rs2236907, rs861019 and rs1044516 of the IRF6 gene were analyzed. The genotype and allele frequencies of the SNP rs2235371 showed significant differences in patients with cleft palate when compared to the control group. However, no association was observed between SNPs rs642961, rs2236907, rs861019 and rs1044516 and nonsyndromic orofacial clefts [42]. However, this association must be interpreted with care due to the low number of studied individuals.

Reference [6] observed that changes in the MTHFR and RBP4 genes, that code for enzymes involved in the biosynthesis of folic acid and vitamin A, have a high contribution to the incidence of cleft lip/palate. These results are consistent with the notion that folic acid and vitamin A are essential nutritional supplements for pregnant women in order to reduce the risk of conceiving a baby with cleft lip/palate.

Reference [28] classified candidate genes as possibly associated with the phenotype of oral clefts in humans, according to the molecular function of the gene, with the biological and family genetic process (genetic inheritance). 
The genes and associated molecular functions are: molecular signaling (FGF1, FGF19, FGF2, JAG2, NOG, PDGFC, $S P R Y 2$ genes), growth factor (FGF1, FGF19, FGF2, $P D G F C$ genes), transcription factor (ARNT, $L H X 8, T B X 10$, ARX, ESR1, JAG2, PAX7, RARA, SPRY2, MAFB, MKX genes), transferase (NAT1, NAT2, GSTT1, COMT genes), extra-cellular matrix (COL8A1, MMP9, NTN1, NOG genes). Genes related to biological processes are: development process (RYK, TBX10, ARX, ESR1, FGF1, FGF19, FGF2, LHX8, MYH9, NTN1, NOG, PAX7, PDGFC, RARA, SPRY2, $M A F B, P D G F R A$ genes); mesoderm development (FGF1, FGF2, MYH9, NOG, SPRY2 genes); neurogenesis (RYK, ARX, FGF19, JAG2, LHX8, NTN1, PAX7, MAFB genes); ectoderm development (RYK, ARX, FGF19, JAG2, LHX8, NTN1, PAX7, MAFB genes); specific segments ( $A R X, P A X 7$ genes); skeletal development (NOG gene); muscle development (MYH9 gene); oncogenesis (RARA, PDGFRA, $S T 5$ genes). The genes related to family genetics (genetic inheritance) are: protein chain ( $A R X, P A X 7, L H X 8, M K X$ genes); heparin binding ( $F G F 1, F G F 2, F G F 19$ genes); related patterns (DISP1 gene); neurotransmitter channel blocker (GABRB3 gene); protein tyrosine kinase ( $R Y K$ gene); $\mathrm{N}$-hydroxyarylamine o-acetyltransferase (NAT1, NAT2 genes); tropomyosin (MYH9 gene).

\section{Environmental Factors Involved in Cleft Lip/Palate Development}

The multifactorial etiology of congenital malformations is well studied. Thus, in addition to genetic factors, its occurrence may be related to the exposure of the child, even before birth, or even of his parents, to toxic substances, such as tobacco [46]-[49]. Several studies indicate that children of mothers who smoke during pregnancy have a higher risk of developing some type of congenital malformation [46]. Significant associations were found between maternal smoking during pregnancy and congenital malformations of the cardiovascular, digestive, musculoskeletal and face and neck systems [50].

In several studies, smoking during pregnancy has been associated with orofacial clefts [4] [46] [47] [51]-[53]. However, most studies have failed to assess the relationship between maternal smoking and specific phenotypes (for example, bilateral clefts).

Reference [48] analyzed the association between periconceptional maternal smoking, environmental exposure to tobacco smoke and cleft lip with or without cleft palate and cleft palate alone compared to babies without birth defects. It was observed that periconceptional smoking was associated with cleft lip/palate and more strongly associated with bilateral cleft lip/palate. Intense maternal smoking (more than 25 cigarettes/day) was associated with cleft lip with or without cleft palate, cleft lip with or without bilateral cleft palate and cleft palate with Pierre Robin sequence. This study confirmed the modest association between smoking and orofacial clefts [48].

Reference [50] found a significant positive association between maternal smoking and malformations of several systems, including the face and neck. The study showed that the strength of association between maternal smoking and malformations in the fetus is significantly related to the daily amount of consumed cigarettes [46] [49] [54]-[57].
Reference [58] investigated the association between SNPs rs7525173, rs2236518 and rs2493264 of the PRDM16 gene and smoking, alcohol exposure and non-syndromic cleft lip with/without cleft palate. The results showed that the rs2236518 polymorphism in this gene, passive maternal smoking (or not) and maternal alcohol consumption were closely related to the occurrence of non-syndromic cleft lip/palate [58].

On the other hand, a study in a Brazilian population found no association between certain polymorphisms, environmental factors, and the appearance of a nonsyndromic oral cleft [1]. In this study, the use of tobacco and alcohol during pregnancy was analyzed. There was no evidence of association between the TGFA/Taq I polymorphisms and the presence of clefts. There was also no association between these polymorphisms and environmental factors (alcohol and/or tobacco). However, larger sampling would be needed to confirm these results.

Reference [59] investigated whether there is an association between parental consanguinity and the occurrence of oral cleft in their children. A positive association rate $(2.68 \%)$ was observed compared to the control group which showed only $0.79 \%$ of association. The difference found between the groups was statistically significant. The most frequent degree of kinship in cases of consanguineous marriages, in both groups, was among first cousins. The most frequent types of clefts in children were cleft palate or cleft lip alone. In the studied population, parental consanguinity was associated with the occurrence of non-syndromic oral cleft and can be considered an isolated risk factor in this population.

According to Reference [60], some malformations are clearly associated with more advanced maternal age. However, the effect of older father age is still uncertain. The aim of this study was to determine the extent to which maternal and paternal age independently influence the risk of having a child with an orofacial cleft. Separate analyses of the mother's and father's age showed that older age was associated with an increased risk of cleft lip with or without cleft palate and cleft palate only. In a joint analysis, maternal and paternal ages were associated with the risk of cleft lip with or without cleft palate, but the contribution of each depended on the age of the other parent. In the analysis of cleft palate alone, the effect of maternal age disappeared, leaving only paternal age as a risk factor. Both advanced maternal and paternal ages were associated with cleft lip with or without cleft palate. Higher paternal age, but not maternal age, only increased the risk of cleft palate.

Reference [61] stated that previous studies [62]-[64] suggested that preconception maternal occupational exposure to solvents and pesticides increases the risk of oral fissures in children. Little is known about the effect of occupational exposure to metals, dust, gases, and vapors on the development of oral clefts. The analysis of subgroups stratified by gender showed a significantly increased risk for male babies exposed to 'other solvents' and exposure to mineral powder for female babies. The study showed that maternal occupational exposure to pesticides and dust are risk factors for oral fissures in children [61]. 


\section{E. Prevention}

Folic acid is important in preventing neural tube defects, however there is inconclusive evidence that supplementation of folic acid before the start of pregnancy reduces the risk of orofacial clefts. Reference [65] did not observed statistically significant association between the use of folate and the risk of isolated orofacial clefts. However, these researchers reported a lower risk of orofacial clefts that occurred in combination with other malformations, such as congenital abnormalities of the heart, limbs, or urinary tract.

The American Academy of Pediatrics recommends that all women of childbearing age consume $0.4 \mathrm{mg}$ of folic acid daily to avoid two types of serious and common birth defects (spina bifida and anencephaly). Pre-conception folic acid supplementation can also have a protective effect against some types of cleft lip/palate [18].

Reference [66] examined the gene-environment interaction between the C667T polymorphism of the MTHFR gene, which encodes the methylenetetrahydrofolate reductase enzyme, and folic acid in the etiology of orofacial clefts. The results showed a reduced risk of cleft lip with or without cleft palate, with the use of maternal folic acid and with supplements containing folic acid. Maternal smoking increased the risk of cleft lip with or without cleft palate. No significant risks were observed in maternal or fetal genotypes regarding the C677T polymorphism [66].

\section{MALOCCLUSION}

Balanced facial growth is essential for a harmonious, wellproportioned face with normal occlusion. Understanding the mechanisms involved in the growth and development of the face provides the possibility of obtaining better results when treating some facial dysmorphology [67].

Reference [68] stated, "(...) that the first maxillary molars were the key to occlusion and that the maxillary and mandibular molars should relate so that the mesiobuccal cusp of the maxillary molar would occlude in the buccal sulcus of the mandibular molar and the teeth were arranged in a smooth occlusion curve, so a normal occlusion would result" [69].

Malocclusion is not considered a disease, but rather a morphological condition that affects the growth and development of the facial bones and muscles. It can produce changes both at the aesthetic level, in the teeth and face, which can result in a distorted facial appearance, as well as at the functional level, in the act of chewing, swallowing food and phonation, and in an increased risk for trauma at the dental level, thus compromising the patient's quality of life [67].

Malocclusion can occur as a result of several factors and be related to habits that are established in childhood [70]. For Reference [67], malocclusion is a heterogeneous condition with a multifactorial etiology, present in approximately 60$70 \%$ of the population.

Based on the occlusal relationships of the first molars, malocclusion was classified according to reference [68] into three classes [69]:

Class I: Normal molar relationship, but with an incorrect occlusion line due to poor dental positioning, rotations, or other causes.
Class II: Lower molar distally positioned in relation to the upper molar.

Class III: Lower molar medially positioned in relation to the upper molar.

Other types of malocclusion are also described in the literature, such as the case of posterior crossbite, which is a deviation from the ideal occlusion in the transversal plane, and overbite and open bite, which are malocclusions in the vertical plane.

Severe malocclusion is a change at the dental and skeletal level, which can lead to a distorted facial appearance, limited masticatory function, an increased risk of dental trauma, compromising the individual's quality of life [11]. There are several estimates of high frequency of malocclusions with approximately one third of the population in need of treatment [71].

\section{A. Open Bite}

Reference [72] determined open bite as a type of malocclusion and different authors have established that it occurs when the overbite is less than the normal overbite. Depending on the location of the open bite, it can be a posterior open bite or anterior open bite [73].

The posterior open bite can be defined as a failure in the contact of the upper posterior teeth with the antagonists when one is in centric occlusion and one has a normal overbite [73].

Anterior open bite is defined as a negative vertical overlap where there is no contact between the edges of the upper incisor teeth and the lower incisor teeth [9] [74]. For reference [75], anterior open bite can occur in the same way with a class I, class II or class III skeletal pattern.

There is no consensus in the literature on the exact definition of anterior open bite, although it appears that this anomaly has distinct characteristics that are easily recognized [76]. The anterior open bite is defined as nonocclusal contact between the lower and upper incisors. The incidence of anterior open bite varies between different ethnicities and with dental age, with values between 1.5 and $11 \%$.

According with reference [77], anterior open bite is a multifactorial malocclusion that can be dentoalveolar, skeletal or combined, observed in the vertical plane.

Dental open bite is characterized by presenting buccal teeth, without alteration of the bone bases and does not extend beyond the canine. It is usually found in the anterior region, being associated with a normal craniofacial pattern, proclaimed anterior teeth and finger sucking habits. Patients have a normal facial morphology and a correct bone relationship.

Skeletal open bite is characterized by hyper divergence in the maxilla, with the lower facial third and increased vertical dimension [73]. It is often related to the excessive growth of the dentoalveolar complex in the vertical plane [78].

The treatment of an open bite can be exceedingly difficult for orthodontists, as this change develops as a result of the interaction of many etiological factors [79].

\section{B. Genetic Factors Determining Open Bite}

Like any other malocclusion, the anterior open bite can also be the result of factors of hereditary origin that can act in the orofacial tissues at the prenatal or postnatal level [73]. For 
Reference [77], it is possible that the anterior open bite is influenced by genetic factors, since the genes that contribute to the growth and development of bones, teeth and soft tissues may be associated with the anterior open bite.

According with reference [11], several data sources suggest that genetic factors contribute to the development of malocclusions. There may be a moderate to high proportion of inheritance (up to $60 \%$ contribution) for many dental and facial features. On the other hand, overbite has 53\% and overjet $28 \%$ of genetic contribution, which suggests that environmental factors have a greater contribution than genetic factors.

As for malocclusions and facial deformations, genetics can explain many of the variations seen in a population. However, malocclusion is not determined by a monogenic model, nor is it the case for many human diseases or congenital malformations, among other characteristics of an individual. On the contrary, these traits have complex or multifactorial modes of inheritance, and are also influenced by environmental factors [71].

\section{Genes Involved in the Development of Soft Tissues}

The genes encoding MMPs and TIMPs are expressed in osteoblasts and are involved in bone development, molding, and tissue remodeling, playing an especially important role during organogenesis [77]. MMPs are a group of enzymes responsible for the degradation and cleavage of most proteins in the extracellular matrix during growth, being inhibited by TIMPs [80].

Reference [77] concluded that the rs 17576 polymorphism of the MMP9 gene (substitution of the amino acid glutamine for arginine) is associated with the development of anterior open bite. These authors showed that the GG genotype is a protective factor for the development of anterior open bite.

Reference [81] demonstrated that the genetic alterations that lead to variations in the type of muscle fibers, namely in the masseter muscle, may be associated with malocclusions and facial asymmetries.

Skeletal muscle cells produce many proteins that, when combined, define the unique characteristics and functions of muscle fiber tissues. The main protein responsible for the speed of contraction of muscle fibers is the myosin heavy chain (MHC), and four types of muscle fibers can be described, type I, type IIA, type IIX and type I/II. In addition, there are also skeletal muscle proteins such as $\alpha$-actin- 2 and $\alpha$-actin-3 (fast twitch fiber or type II). Studies have shown that an increased vertical dimension is inversely related to type II muscle fibers, that is, anterior open bite or increased vertical dimension is associated with type I muscle fibers (of slow contraction) that can be found in the masseter muscle [82].

The genes encoding $\alpha$-actin in all fibers were tested, with $A C T N 2$ being expressed in all fibers and $A C T N 3$ in fasttwitch fibers (type II). There is a genetic variant, R577X, in the gene coding for $\alpha$-actin, which may be associated with malocclusion in the sagittal and vertical plane. It was observed that individuals with class II malocclusion had two mutant copies (R 577X) and fewer type II muscle fibers [71]. Another gene involved in the development of tissues is the $A J U B A$ gene, a member of the family of proteins with the LIM signal that contributes to the determination of the prosthetic fate in the cell. In rats, the $A J U B A$ gene was expressed early in development in the facial prominences that give rise to the forehead, nose, maxilla, and mandible [67]. In addition, the protein encoded by this gene regulates the signaling cascade that controls embryonic development, activating proliferation and differentiation. It also negatively regulates the signaling pathway of the hypothalamus responsible for controlling tissue size. Therefore, the result of the study of reference [67] constitutes an affirmation of the role of the $A J U B A$ gene in facial variation and in the eruption of primary dentition.

\section{Genes Involved in Facial Bone Growth}

Estrogens and androgens are key hormones for skeletal growth and maturation and maintenance of bone mass. An increase in estrogens/androgens promotes pubertal growth, decreasing the formation of osteoclasts and increasing the formation and proliferation of osteoblasts. The CYP19A1 gene encodes the aromatase enzyme (estrogen synthetase) responsible for converting testosterone to estrogen. Single nucleotide polymorphisms (SNPs) of this gene, could influence the sagittal growth of the mandible. Thus, He et al. [83] tested this association in individuals with class I skeletal malocclusion and concluded that the rs2470144 and rs2445761 polymorphisms have a significant association with the sagittal growth of the mandible.

Reference [82] observed a significant difference in the growth of the mandible in the sagittal plane, when they compared groups of Caucasian men with a genetic variation in the CYP19A1 gene with groups of women who inherited the same genetic variation. It was observed that the group of men showed more significant differences in facial growth than the group of women, suggesting that the variant of the CYP19A1 gene may be a multiethnic marker for the sagittal growth of the male mandible.

Reference [82] also showed that individuals with polymorphisms (Pro561Thr) in the growth hormone receptor (GHR) coding gene, had differences in the length of the mandibular branch (condyle-gonium) and variation in skeletal growth. This study showed that the group that presented this polymorphism had a significantly shorter mandibular branch length than the group that did not have this allelic variation.

Recent studies [84] have identified members of the TNF- $\alpha$ family and their receptors, as essential regulators of osteoclastogenesis. RANKL/RANK signaling regulates the formation of osteoclasts including bone modeling and remodeling. OPG protects the bone from excessive resorption when it binds to RANKL, preventing it from binding with RANK, forming the apposition and bone reduction screening. These studies have shown that the rs3826620 polymorphism of the RANK gene is associated with the size of the mandibles.

\section{E. Genes Involved in the Development or Eruption of Teeth}

Failure in tooth eruption appears to have an autosomal dominant inheritance with variable expressiveness that can be seen mainly in permanent dentition, but there are also examples in primary dentition. The appearance of this phenotype in $1 / 4$ of all individuals in a family, helped to investigate the mutations in the PTHRl gene. This gene is found on chromosome 3, with more than 25 unique mutations associated with failure in the eruption, and 
mutations that lead to premature protein synthesis stop leading to protein truncation and consequent haploinsufficiency [82].

In class I malocclusions, the SNP rs6504340 described in the $H O X B$ cluster was associated with late tooth eruptions and occlusion irregularities [11].

\section{F. Environmental Factors of Open Bite}

Facial growth and craniofacial morphology are influenced by genetic and environmental factors. Changes in the intensity of growth and development of soft tissues and muscle function can influence alveolar development, causing malocclusion in the vertical plane [85].

Open bite, like any other malocclusion, is multifactorial and results from the interaction of several etiological factors. These factors can be divided into genetic and environmental factors [9].

Environmental factors play an especially important role in the development of a patient's morphofacial changes [84]. Among these factors there are functional etiological factors such as deleterious mouth habits and mouth breathing. Other factors that also influence are trauma and certain pathologies [9].

The presence of some oral habits is one of the most important factors involved in the development of dentomaxillofacial anomalies. Habits are an acquired practice that occurs through the frequent repetition of the same act, which is initially done in a conscious way, but soon becomes unconscious. Among the most common habits in childhood, especially between 0 and 3 years of age, is pacifier sucking followed by digital sucking [86]. All habits involve an obstruction mechanics and a lack of contact that causes the eruption to be prevented or that allows a supraeruption of the teeth [79].

The anterior open bite was associated with the continued presence of non-nutritive sucking habits, mouth breathing and lingual interposition [86].

\section{G. Pacifier Sucking and Digital Sucking}

Breastfeeding is seen as a determining factor in craniofacial development, as it promotes intense exercise of the orofacial muscles in addition to stimulating breathing, swallowing, chewing and phonation [86]. But when for different reasons breastfeeding is replaced by a baby bottle, children do not perform the same exercise. They suppress their physiological need for food, but not their natural need to suck, which is why children begin to compensate with pacifier sucking and digital sucking.

In childhood many children develop the habit of sucking non-nutritious from a finger or a pacifier and in this period, it is considered to have no effect on primary dentition in the long run. If the habit persists when the eruption of permanent teeth begins, it can probably result in a type of malocclusion, specifically in the open bite [69].

According with reference [86], children who have the habit of digital sucking or pacifier, as well as those with a low breastfeeding rate are more susceptible to presenting an open bite.

The use of the baby bottle causes a decrease in the work of the jaw. The movements that are made are vacuum with the tongue, cheeks and lips that cause the tongue to press the teat of the bottle against the palate, thus generating a deeper palate. The buccal inclination of the upper incisors, their separation from each other and the lingual inclination of the lower incisors are characteristic of anterior open bite malocclusion using pacifiers [9].

Regarding digital sucking, some children put their thumb or other finger between their teeth resting passively, while others actively suck. The duration, continuity and intensity of the habit will result in the establishment of malocclusion [73]. The finger is placed at an angle in the oral cavity which causes it to occur in the same way as with the suction of the pacifier. In addition, there may be variation of the affected teeth according to the position as the finger is inserted into the mouth.

\section{H. Lingual Interposition}

Lingual interposition is the most prevalent oral habit that explains the occurrence of open bite [70]. During swallowing, the wrong position of the tongue forward when interposing between the anterior teeth may explain the occurrence of an open bite [76].

Swallowing is not a learned habit, but a conscious act that has two phases. Infant swallowing where the jaws are separated, the lips have a muscular contraction and the position of the tongue is between the gingival edges in contact with the lower lip. Around 3 years of age, the mature swallowing phase occurs. When children complete their primary dentition, the teeth enter occlusion, the tip of the tongue meets the incisor papilla and the labial musculature remains passive during swallowing [9].

On the contrary, when an anterior open bite is present, swallowing is not done in the same way, as it becomes more difficult to close the lips to prevent liquid food from escaping the oral cavity. That is why the tongue is placed between the teeth and close to the lips making the sealing maneuver.

According to reference [76] the force of the lingual interposition during swallowing can last for about 20 minutes a day, which is not enough to deviate the position of the teeth. For reference [9], the factor to be considered is the wrong position of the tongue when it is at rest, as it can contribute to malocclusion. Although the strength is slight, it remains between the teeth for a long period of time.

\section{Mouth Breathing and Muscle Tone}

Some pathologies can trigger mouth breathing. Nasal airway obstruction resulting from allergic rhinitis, adenoid hyperplasia or hyper-spun palatine tonsils can trigger this condition [76]. Reference [69] points out that to be able to breathe through the mouth the patient must lower the jaw, the tongue and extend the head back.

In turn, reference [9] explain, “(...) that children with mouth breathing remain most of the time with their jaws in a low position, in order to keep their mouths open, the tongue in turn accompanies the jaw and, therefore, does not establish contact with the palate as it should be in a resting position". Reference [87] argues that modern diets are nowadays relatively milder than before, which resulted in a significant reduction in the muscle forces used in chewing.

There is controversy about the relationship between the muscles and the open bite. Bone formation is influenced by facial muscles at their insertion points. When there is little muscle activity, the plans may diverge and thus develop an 
open bite. Weak muscular forces supposedly lead to the supra-eruption of the posterior buccal segment [76].

\section{J. Trauma and Pathologies}

The types of trauma that can affect occlusion are dentoalveolar or skeletal-facial. In patients with primary dentition, the forces involved in trauma can cause ankylosis in the permanent dentition, resulting in an absent overbite, that is, an open bite [76]. For reference [9], ankylosis resulting from some type of lesion in the primary dentition can cause tooth retention, delayed or ectopic eruption of the permanent successor, thus leading to an open bite.

Condylar resorption is also identified as an etiological factor of anterior open bite and many local or systemic diseases can cause it, such as osteoarthritis, arthritis, reactive arthritis, avascular necrosis, infections, and trauma. Autoimmune diseases such as scleroderma, lupus erythematosus, rheumatoid arthritis, Sjogren's syndrome, ankylosing spondylitis and psoriatic arthritis can also be a cause of anterior open bite.

\section{DISCUSSION AND CONCLUSION}

The multifactorial character of orofacial congenital malformations has been discussed and explored in numerous studies [1] [2] [4] [6] [28] [39] [42] [46]-[48] [50]-[53]. In most cases, genetic and environmental factors do not act as isolated events and determinants of congenital malformations. There is an association of such factors that favors the development of congenital malformations, such as cleft lip/palate [3] [16].

As previously discussed, cleft lip/palate have a complex and multifaceted etiology, with the contribution of both genetic and environmental factors, such as smoking during pregnancy, second-hand smoke (or not) by the pregnant woman, alcohol, parents advanced age, inbreeding, use anticonvulsants and exposure to pesticides and harmful products [4] [20] [48] [50] [58] [60] [88]-[93].

Regarding the genetic components involved in orofacial malformations, the studies by references [2], [39], [28], [6] and [42] corroborate their results because they present scientific evidence based on significant populations. However, studies by reference [1], showed different results, where no evidence was found that the TGFA/Taq I polymorphisms play a role in the gap in this population, which suggests the need for a larger sample to confirm these results.

Taking into account the environmental elements, a clear influence was observed in the studies by references [46], [47], [48], [51], [50], [52], [4] and [53], with smoking being the most commonly found factor with strong scientific evidence.

In view of the above, it is possible to conclude that congenital malformations, such as cleft lip/palate in nonsyndromic patients, have a complex multifactorial etiology, involving environmental and genetic factors. In the same way, anterior open bite is a multifactorial trait and numerous hypotheses have been proposed to explain this characteristic, considering genetic and environmental factors.

The management of cleft lip/palate requires a multidisciplinary approach involving medical surgical interventions, nutritional monitoring, dental treatment, and speech and behavioral treatments. The ideal treatment is difficult to find, due to the great variability of malformations and the subjective response of each patient to therapy. The anterior open bite is the most complicated of all malocclusions. Various treatment modalities should be used depending on their etiology. This topic is overly complex, so in the future it should be the subject of more studies in order to be able to give a better treatment to patients.

\section{REFERENCES}

[1] L. T. Souza, T. W. Kowalski, A. P. Vanz, R. Giugliani, and T. M. Félix, "TGFA/Taq I polymorphism and environmental factors in nonsyndromic oral clefts in Southern Brazil." Brazilian Oral Research, vol. 26, no. 5, pp. 431-435, September-October 2012. http://dx.doi.org/10.1590/S1806-83242012005000016.

[2] P. Garg, K. U. Ludwig, A. C. Bohmer, M. Rubini, R. Steegers-Theunissen, P. A. Mossey, et al. "Genome-wide analysis of parent-of-origin effects in non-syndromic orofacial clefts." European Journal of Human Genetics, vol. 22, no. 6, pp. 822-830, June 2014. https://oi.org/10.1038/ejhg.2013.235.

[3] M. J. Dixon, M. L. Marazita, T. H. Beauty, and J. C. Murray, "Cleft lip and palate: understanding genetic and environmental influences." Nature Reviews Genetics, vol. 12, no. 3, pp. 167-178, March 2011. https://doi.org/10.1038/nrg2933.

[4] H. J. Sabbagh, M. H. Hassan, N. P. Innes, H. M. Elkodary, J. Little, and P. A. Mossey, "Passive smoking in the etiology of non-syndromic orofacial clefts: a systematic review and meta-analysis." PLoS One, vol. 10, no. 3, pp. e0116963, March 2015. https://doi.org/10.1371/journal.pone.0116963.

[5] R. Jiang, J. O. Bush, and A. C. Lidral, "Development of the upper lip: morphogenetic and molecular mechanisms." Developmental Dynamics, vol. 235, no. 5, pp. 1152-1166, May 2006. https://doi.org/10.1002/dvdy.20646.

[6] S. J. Zhang, P. Meng, J. Zhang, P. Jia, J. Lin, X. Wang, et al. "Machine learning models for genetic risk assessment of infants with nonsyndromic orofacial cleft." Genomics Proteomics \& Bioinformatics, vol. 16, no. 5, pp. 354-364, October 2018. https://doi.org/10.1016/j.gpb.2018.07.005.

[7] L. C. D. Silva, S. A. S. Vedovello, M. Vedovello Filho, M. C. Meneghin, G. M. Ambrosano Bovi, and V. V. Degan, "Anxiety and oral habits as factors associated with malocclusion." Cranio: The Journal of Craniomandibular Practice, vol. 23, pp. 1-5, June 2019. https://doi.org/10.1080/08869634.2019.1633492.

[8] P. Frazão, P. C. Narvai, Mdo. R. Latorre, and R. A. Castellanos, "Malocclusion prevalence in the deciduous and permanent dentition of schoolchildren in the city of São Paulo, Brazil, 1996." Cadernos de Saúde Pública, vol. 18, no. 5, pp. 1197-1205, September-October 2002. https://doi.org/10.1590/s0102-311×2002000500012.

[9] G. Janson, and F. Valarelli, Mordida aberta tratamento e estabilidade. Maringa, Dental Press editora, 2016.

[10] E. C. Kuchler, D. Barreiros, R. O. Silva, J. G. B. Abreu, E. C. Teixeira, R. A. B. Silva, et al. "Genetic polymorphism in MMP9 may be associated with anterior open bite in children." Brazilian Dental Journal, vol. 28, no. 3, pp. 277-280, May-June 2017. https://doi.org/10.1590/0103-6440201600992.

[11] L. M. Moreno Uribe, and S. F. Miller, "Genetics of the dentofacial variation in human malocclusion." Orthodontics \& Craniofacial Research, vol. 18, no. Suppl 1, pp. 91-99, April 2015. https://doi.org/10.1111/ocr.12083.

[12] M. L. Marazita, "The evolution of human genetic studies of cleft lip and cleft palate." Annual Review of Genomics and Human Genetics, vol. 13, pp. 263-283, June 2012. https://doi.org/10.1146/annurev-genom090711-163729.

[13] E. J. Leslie, and M. L. Marazita, "Genetics of cleft lip and cleft palate." American Journal of Medical Genetics Part C, Seminars in Medical Genetics, vol. 163C, no. 4, pp. 246-258, November 2013. https://doi.org/10.1002/ajmg.c.31381.

[14] G. Farronato, P. Cannalire, G. Martinelli, I. Tubertini, L. Giannini, G. Galbiati, et al. "Cleft lip and/or palate: review." Minerva Stomatology, vol. 63, no. 4, pp. 111-126, April 2014.

[15] A. R. Borges, L. Mariano, J. Sá, A. P. Medrado, P. C. Veiga, and S. R. A. Reis, "Fissuras labiais e/ou palatinas não sindrômicas determinantes 
ambientais e genéticos." Revista Bahiana de Odontologia, vol. 5, no. 1, pp. 48-58, January 2014.

[16] T. Wu, K. Y. Liang, J. B. Hetmanski, I. Ruczinski, M. D. Fallin, R. G. Ingersoll, et al. "Evidence of gene-environment interaction for the IRF6 gene and maternal multivitamin supplementation in controlling the risk of cleft lip with/without cleft palate." Human Genetics, vol. 128, no. 4, pp. 401-410, October 2010. https://doi.org/10.1007/s00439-010-0863y.

[17] P. A. Mossey, and J. Little, Epidemiology of oral clefts: an international perspective. In: Wyszynski DF, editor. Cleft lip and palate: from origin to treatment. Oxford: Oxford University Press, 2002, pp. 127-158.

[18] C. W. Lewis, L. S. Jacob, C. U. Lehmann, and APP Section on Oral Health. "The primary care pediatrician and the care of children with cleft lip and/or cleft palate." Pediatrics, vol. 139, no. 5, pp. e20170628, May 2017. https://doi.org/10.1542/peds.2017-0628.

[19] P. A. Mossey, J. Little, R. G. Munger, M. J. Dixon, and W. C. Shaw, "Cleft lip and palate." Lancet, vol. 374, pp. 1773-1785, November 2009. https://doi.org/10.1016/S0140-6736(09)60695-4.

[20] L. A. Brito, J. G. Meira, G. S. Kobayashi, and M. R. Passos-Bueno, "Genetics and management of the patient with orofacial cleft." Plastic Surgery International, vol. 2012, pp. 782821, November 2012. https://doi.org/https://doi.org/10.1155/2012/782821.

[21] P. Fogh-Andersen, Inheritance of Harelip and Cleft Palate. Copenhagen: Munksgaard, 1942

[22] F. C. Fraser, "Thoughts on the etiology of clefts of the palate and lip." Acta Genetica et Statistica Medica, vol. 5, no. 4, pp. 358-369, 1955.

[23] D. Grosen, C. Bille, I. Petersen, A. Skytthe, J. Hjelmborg, J. K. Pedersen, et al. "Risk of oral clefts in twins." Epidemiology, vol. 22, no. 3, pp. 313-319, May 2011. https://doi.org/10.1097/EDE.0b013e3182125f9c.

[24] F. Rahimov, M. L. Marazita, A. Visel, M. E. Cooper, M. J. Hitchler, M Rubini, et al. "Disruption of an AP-2a binding site in an IRF6 enhancer is associated with cleft lip." Nature Genetics, vol. 40, pp. 1341-1347, November 2008. https://doi.org/10.1038/ng.242.

[25] K. U. Ludwig, E. Mangold, S. Herms, S. Nowak, H. Reutter, A. Paul et al. "Genome-wide meta-analyses of nonsyndromic cleft lip with or without cleft palate identify six new risk loci." Nature Genetics, vol. 44, no. 9, pp. 968-971, September 2012. https://doi.org/10.1038/ng.2360.

[26] F. Rahimov, A. Jugessur, and J. C. Murray, "Genetics of nonsyndromic orofacial clefts." The Cleft Palate Craniofacial Journal, vol. 49, no. 1, pp. 73-91, January 2012. https://doi.org/10.1597/10-178.

[27] H. Tian, J. Feng, J. Li, T. V. Ho, Y. Yuan, F. Brindopke, et al. "Intraflagellar transport 88 (IFT88) is crucial for craniofacial development in mice and is a candidate gene for human cleft lip and palate." Human Molecular Genetics, vol. 26, no. 5, pp. 860-872, March 2017. https://doi.org/10.1093/hmg/ddx002.

[28] N. Funato, and M. Nakamura, "Identification of shared and unique gene families associated with oral clefts." International Journal of Oral Sciences, vol. 9, no. 2, pp. 104-109, June 2017. https://doi.org/10.1038/ijos.2016.56.

[29] B. Antoszewski, and M. Fijałkowska, "Distribution of types of lip and/or palate clefts among children from Lodz during years 1981-2015." Polski Przeglad Chirurgiczny, vol. 90, no. 3, pp. 1-4, May 2018. https://doi.org/10.5604/01.3001.0011.8162.

[30] C. J. Trew, "Sistens plura exempla palati deficientes." Nova Acta Physico-Medica Academiae Caesarae Leopoldion-Carolinae, vol. 1, pp. 445-447, 1757.

[31] J. Sproule, "Hereditary nature of hare-lip.” British Medical Journal, vol. 1, pp. 412,1863

[32] C. Darwin, The variation of animals and plants under domestication. London, England: John Murray, Albermarle Street, 1875.

33] M. L. Marazita, M. A. Spence, and M. Melnick, "Genetic analysis of cleft lip with or without cleft palate in Danish kindreds." American Journal of Medical Genetics, vol. 19, no. 1, pp. 9-18, September 1984 https://doi.org/10.1002/ajmg.1320190104.

[34] L. E. Mitchell, Mode of inheritance of oral clefts. In: Wyszyski, DF., editor. Cleft Lip and Palate: from origin to treatment. Oxford University Press, 2002, pp. 234-239.

[35] A. Sivertsen, A. J. Wilcox, R. Skjaerven, H. A. Vindenes, F. Abyholm, E. Harville, et al. "Familial risk of oral clefts by morphological type and severity: population based cohort study of first degree relatives." British Medical Journal, vol. 336, no. 7641, pp. 432-434, February 2008. https://doi.org/10.1136/bmj.39458.563611.

[36] J. Little, and E. Bryan, "Congenital anomalies in twins." Seminars in Perinatology, vol. 10, no. 1, pp. 50-64, January 1986.

[37] F. Carinci, L. Scapoli, A. Palmieri, I. Zollino, and F. Pezzetti, "Human genetic factors in nonsyndromic cleft lip and palate: an update.'
International Journal of Pediatric Otorhinolaryngology, vol. 71, no. 10, pp. 1509-1519, October 2007. https://doi.org/10.1016/j.ijporl.2007.06.007.

[38] Y. P. Liu, L. F. Xu, Q. Wang, X. L. Zhou, C. Pan, J. P. Zhang, et al. "Identification of susceptibility genes in non-syndromic cleft lip with or without cleft palate using whole-exome sequencing." Medicina Oral, Patologia Oral y Cirugía Bucal, vol. 20, no. 6, pp. e763-770, October 2015. https://doi.org/10.4317/medoral.20758.

[39] E. J. Leslie, J. C. Carlson, J. R. Shaffer, E. Feingold, G. Wehby, C. A. Laurie et al. "A multi-ethnic genome-wide association study identifies novel loci for non-syndromic cleft lip with or without cleft palate on 2p24.2, 17q23 and 19q13." Human Molecular Genetics, vol. 25, no. 13 pp. 2862-2872, July 2016. https://doi.org/10.1093/hmg/ddw104.

[40] A. Jamilian, F. Sarkarat, M. Jafari, M. Neshandar, E. Amini, S. Khosravi, et al. "Family history and risk factors for cleft lip and palate patients and their associated anomalies." Stomatologija, vol. 19, no. 3, pp. 78$83,2017$.

[41] X. Ge, J. W. Hong, J. Y. Shen, Z. Li, R. Zhang, Q. Wang, et al. "Investigation of candidate genes of non-syndromic cleft lip with or without cleft palate, using both case-control and family-based association studies." Medicine, vol. 98, no. 26, pp. e16170, June 2019. https://doi.org/10.1097/MD.0000000000016170.

[42] J. F. Bezerra, H. P. V. Silva, R. H. Bortolin, A. D. Luchessi, M. A. G. Ururahy, M. B. Loureiro, et al. "IRF6 polymorphisms in Brazilian patients with non-syndromic cleft lip with or without palate." Brazilian Journal of Otorhinolaryngology, https://doi.org/10.1016/j.bjorl.2019.04.011, June 2019.

[43] T. Taniguchi, K. Ogasawara, A. Takaoka, and N. Tanaka, "IRF family of transcription factors as regulators of host defense." Annual Review of Immunology, vol. 19, pp. 623-655, 2001. https://doi.org/10.1146/qnnurev.immunol.19.1.623.

[44] C. R. Ingraham, A. Kinoshita, S. Kondo, B. Yang, S. Sajan, K. J. Trout, et al. "Abnormal skin, limb and craniofacial morphogenesis in mice deficient for interferon regulatory factor 6 (IRF6)." Nature Genetics, vol. 38, pp. 1335-1340, November 2006. https://doi.org/10.1038/ng1903.

[45] C. M. Bailey, D. E. Abbott, N. V. Margaryan, Z. Khalkhali-Ellis, and M. J. Hendrix, "Interferon regulatory factor 6 promotes cell cycle arrest and is regulated by the proteasome in a cell cycle-dependent manner.' Molecular Cell Biology, vol. 28, pp. 2235-2243, April 2008. https://doi.org/10.1128/MCB.01866-07.

[46] K. C. Chung, C. P. Kowalski, H. M. Kim, and S. R. Buchman, "Maternal cigarette smoking during pregnancy and the risk of having a child with cleft lip/palate.” Plastic Reconstruction Surgery, vol. 105, no. 2, pp. 485-491, February 2000. https://doi.org/10.1097/00006534200002000-00001.

[47] J. Little, A. Cardy, and R. G. Munger, "Tobacco smoking and oral clefts: a meta-analysis." Bulletin of the World Health Organization, vol. 82, pp. 213-218, March 2004.

[48] M. A. Honein, S. A. Rasmussen, J. Reefhuis, P. A. Romitti, E. J. Lammer, L. Sun, et al. "Maternal smoking and environmental tobacco smoke and the risk of oral clefts." Epidemiology, vol. 18, pp. 226-233, March 2007. https://doi.org/10.1097/01.ede.0000254430.61294.c0.

[49] P. A. Romitti, L. Sun, M. A. Honein, J. Reefhuis, A. Correa, and S. A. Rasmussen, "Maternal periconceptional alcohol consumption and risk of orofacial clefts." American Journal of Epidemiology, vol. 166, pp. 775-785, October 2007b. https://doi.org/10.1093/aje/kwm146.

[50] D. Nicoletti, L. D. Appel, P. Siedersberger Neto, G. W. Guimarães, and L. Zhang, "Maternal smoking during pregnancy and birth defects in children: a systematic review with meta-analysis." Cadernos de Saúde Pública, vol. 30, no. 12, pp. 2491-2529, December 2014. http://dx.doi.org/10.1590/0102-311x00115813.

[51] J. Grewal, S. L. Carmichael, C. Ma, E. J. Lammer, and G. M. Shaw, "Maternal periconceptional smoking and alcohol consumption and risk for select congenital anomalies." Birth Defects Research: Part A Clinical Molecular Teratology, vol. 82, no. 7, pp. 519-526, July 2008. https://doi.org/10.1002/bdra.20461.

[52] P. Mukhopadhyay, R. M. Greene, and M. M. Pisano, "Cigarette smoke induces proteasomal-mediated degradation of DNA methyltransferases and methyl $\mathrm{CpG}-\mathrm{CpG}$ domain-binding proteins in embryonic orofacial cells.” Reproduction Toxicology, vol. 58, pp. 140-148, December 2015. https://doi.org/10.1016/j.reprotox.2015.10.009.

[53] C. M. Kummet, L. M. Moreno, A. J. Wilcox, P. A. Romitti, L. A. DeRoo, R. G. Munger, et al. "Passive smoke exposure as a risk factor for oral clefts - a large international population-based study." American Journal of Epidemiology, vol. 183, no. 9, pp. 834-841, May 2016. https://doi.org/10.1093/aje/kwv279. 
[54] I. P. Krapels, G. A. Zielhuis, F. Vroom, L. T. de Jong-van den Berg, A. M. Kuijpers-Jagtman, A. B. van der Molen, et al. "Periconceptional health and lifestyle factors of both parents affect the risk of live-born children with orofacial clefts." Birth Defects Research: Part A. Clinical and Molecular Teratology, vol. 76, pp. 613-620, September 2006. https://doi.org/10.1002/bdra.20285.

[55] M. J. van den Boogaard, D. de Costa, I. P. Krapels, F. Liu, C. van Duijn, R. J. Sinke, et al. "The MSX1 allele 4 homozygous child exposed to smoking at periconception is most sensitive in developing nonsyndromic orofacial clefts." Human Genetics, vol. 124, pp. 525534, December 2008.

56] W. Wang, P. Guan, W. Xu, and B. Zhou, "Risk factors for oral clefts: a population-based case-control study in Shenyang, China." Paediatric and Perinatal Epidemiology, vol. 23, no. 4, pp. 310-320, July 2009 https://doi.org/10.1111/j.1365-3016.2009.01025.x.

[57] A. M. Johansen, A. J. Wilcox, R. T. Lie, L. F. Andersen, and C. A. Drevon, "Maternal consumption of coffee and caffeine-containing beverages and oral clefts: a population-based case-control study in Norway." American Journal of Epidemiology, vol. 169, pp. 1216-1222, May 2009. https://doi.org/10.1093/aje/kwp040.

[58] B. Yin, B. Shi, and Z. L. Jia, "Associations among PRDM1 polymorphisms, environmental exposure factors during mother's pregnancy, and nonsyndromic cleft lip with or without cleft palate.' Hua Xi Kou Qiang Yi Xue Za Zhi, vol. 36, no. 5, pp. 503-507, October 2018. https://doi.org/10.7518/hxkq.2018.05.008.

[59] C. M. Silva, M. C. M. Pereira, T. B. Queiroz, and L. T. D. Neves, "Can parental consanguinity be a risk factor for the occurrence of nonsyndromic oral cleft?" Early Human Development, vol. 135, pp. 2326, August 2019a. https://doi.org/10.1016/j.earlhumdev.2019.06.005.

[60] C. Bille, A. Skytthe, W. Vach, L. B. Knudsen, A. M. Andersen, J. C. Murray, et al. "Parent's age and the risk of oral clefts." Epidemiology, vol. 16, no. 3, pp. 311-316, May 2005.

[61] N. Spinder, J. E. H. Bergman, H. M. Boezen, R. C. H. Vermeulen, H Kromhout, and H. E. K. de Walle, "Maternal occupational exposure and oral clefts in offspring." Environmental Health, vol. 16, no. 1, pp. 83 August 2017. https://doi.org/10.1186/s12940-017-0294-5.

62] P. A. Romitti, A. M. Herring, L. K. Dennis, and D. L. Wong-Gibbons, "Meta-analysis: pesticides and orofacial clefts." Cleft Palate Craniofacial Journal, vol. 44, no. 4, pp. 358-365, July 2007a. https://doi.org/10.1597/06-100.1.

[63] S. Cordier, R. Garlantézec, L. Labat, F. Rouget, C. Monfort, N. Bonvallot, et al. "Exposure during pregnancy to glycol ethers and chlorinated solvents and the risk of congenital malformations." Epidemiology, vol 23, no. 6, 806-812, November 2012 https://doi.org/10.1097/EDE.06013e31826c2bd8.

[64] W. Yang, S. L. Carmichael, E. M. Roberts, S. E. Kegley, A. M. Padula, P. B. English, et al. "Residential agricultural pesticide exposures and risk of neural tube defects and orofacial clefts among offspring in the San Joaquin Valley of California." American Journal of Epidemiology, vol. 179, no. 6, pp. 740-748, March 2014 https://doi.org/10.1093/aje/kwt324.

[65] G. M. Shaw, W. Yang, S. Perloff, N. M. Shaw, S. L. Carmichael, H. Zhu, et al. "Thymidylate synthase polymorphisms and risks of human orofacial clefts." Birth Defects Research: Part A. Clinical Molecular Teratology, vol. 97, no. 2, pp. 95-100, February 2013 https://doi.org/10.1002/bdra.23114

[66] A. Butali, J. Little, C. Chevrier, S. Cordier, R. Steegers-Theunissen, A. Jugessur, et al. "Folic acid supplementation use and the MTHFR C677T polymorphism in orofacial clefts etiology: an individual participant data pooled-analysis." Birth Defects Research. Part A, Clinical and Molecular Teratology, vol. 97, no. 8, pp. 509-514, May 2013. https://doi.org/10.1002/bdra.23133.

[67] L. M. Moreno Uribe, A. Ray, D. R. Blanchette, D. V. Dawson, and T. E. Southard, "Phenotype-genotype correlations of facial width and height proportions in patients with Class II malocclusion." Orthodontics and Craniofacial Research, vol. 18, no. Suppl 1, pp. 100-108, April 2015. https://doi.org/10.1111/ocr.12084.

[68] E. Angle, Classification of malocclusion. Philadelphia, Dent. Cosmo, 1898.

[69] G. Proffit, H. Fields, and D. Sarver, Ortodontia Contemporânea. Rio de Janeiro, Elsevier Editorial Ltda, 2012.

[70] D. Priyadarshini, N. Solomon, S. Ravindran, and J. Moses, "Prevalence of oral habits in children and its correlation with malocclusion - a crosssectional study." International Journal of Scientific Research, vol. 8, pp. 14-15, 2019

[71] A. R. Vieira, "Orthodontics and Genetics." Dental Press Journal of Orthodontics, vol. 24, no. 2, pp. 92-97, May 2019.
[72] J. H. Parker, "The interception of the open bite in the early growth period." Angle Orthodontic, vol. 41, no. 1, pp. 24-44, January 1971. https://doi.org/10.1043/00033219(1971)041<0024:TIOTOB $>2.0 . \mathrm{CO} ; 2$.

[73] M. A. Wajid, P. Chandra, R. kulshrestha, K. Singh, R. Rastogi, and V. Umale, "Open bite malocclusion: an overview." Journal of Oral Health and Craniofacial Science, vol. 3, no. 1, pp. 011-020, December 2018. https://doi.org/10.29328/journal.johcs.1001022.

[74] J. Moyers, "Does monitoring have an effect on patient safety? Monitoring instruments are no substitute for careful clinical observation." Journal of Clinical Monitoring, vol. 4, no. 2, pp. 107-111, April 1988.

[75] D. A. Lentini-Oliveira, F. R. Carvalho, C. G. Rodrigues, Q. Ye, L. B. Prado, G. F. Prado, et al. "Orthodontic and orthopaedic treatment for anterior open bite in children." The Cochrane Database of Systematic Reviews, vol. 9, pp. CD005515, September 2014. https://doi.org/10.1002/14651858.CD005515.pub3.

[76] C. Rijpstra, and J. A. Lisson, "Etiology of anterior open bite: a review." Journal of Orofacial Orthopedics, vol. 77, no. 4, pp. 281-286, July 2016. https://doi.org/10.1007/s00056-016-0029-1.

[77] E. C. Küchler, D. Barreiros, R. O. D. Silva, J. G. B. Abreu, E. C. Teixeira, L. A. B. D. Silva, et al. "Genetic polymorphism in MMP9 may be associated with anterior open bite in children." Brazilian Dental Journal, vol. 28, no. 3, pp. 277-280, May-June 2017. http://dx.doi.org/10.1590/0103-6440201600992.

[78] K. J. Lin, A. A. Mitchell, W. P. Yau, C. Louik, and S. Hernandez-Díaz, "Maternal exposure to amoxicillin and the risk of oral clefts." Epidemiology, vol. 23, no. 5, pp. 699-705, September 2012 https://www.jstor.org/stable/41739649.

[79] Mde. C. Cabrera, C. A. Cabrera, K. M. de Freitas, G. Janson, and M. R. de Freitas, "Lateral open bite: Treatment and stability." American Journal of Orthodontics and Dentofacial Orthopedics, vol.137, no. 5 , pp. 701-711, May 2010. https://doi.org/10.1016/j.ajodo.2007.11.037.

[80] M. Rohani, and W. Parks, "Matrix remodeling by MMPs during wound repair." Matrix Biology, vol. 44-46, pp. 113-121, May-July 2015. https://doi.org/10.1016/j.matbio.2015.03.002.

[81] J. J. Sciote, M. J. Horton, A. M. Rowlerson, J. Ferri, J. M. Close, and G. Raoul, "Human masseter muscle fiber type properties, skeletal malocclusion, and muscle growth factor expression." Journal of Oral and Maxilofacial Surgery, vol. 70, no. 2, pp. 440-448, February 2012. https://doi.org/10.1016/j.joms.2011.04.007.

[82] J. Hartsfield, G. Jeryn, and L. Morford, "Heredity, genetics and orthodontics- How much has this research really helped?" Seminars in Orthodontics, vol. 23, no. 4, pp. 336-347, December 2017. https://doi.org/10.1053/j.sodo.2017.07.003.

[83] S. He, J. K. Jr. Hartsfield, Y. Guo, Y. Cao, S. Wang, and S. Chen, "Association between CYP19A1 genotype and pubertal sagittal jaw growth." American Journal of Orthodontics and Dentofacial Orthopedics, vol. 142, no. 5, pp. 662-670, November 2012 https://doi.org/10.1016/j.ajodo.2012.06.014

[84] S. C. Levy, L. A. A. Antunes, J. G. B. Abreu, J. A. D. S. Nascimento, A C. Kuntz, W. L. S. Fialho, et al. "Determination of TNF-a gene polymorphisms on skeletal pattern in Class II malocclusion." Brazilian Dental Journal, vol. 30, no. 2, pp. 152-156, March-April 2019. https://doi.org/10.1590/0103-6440201902367.

[85] G. Farronato, L. Giannini, G. Galbiati, S. A. Stabilini, and C. Maspero, "Orthodontic-surgical treatment: neuromuscular evaluation in open and Deep skeletal bite patients." Progress in Orthodontics, vol. 14, pp. 34 41, October 2013. https://doi.org/10.1186/2196-1042-14-41.

[86] S. A. Moimaz, A. J. Garbin, A. M. Lima, L. F. Lolli, O. Saliba, and C. A. Garbin, "Longitudinal study of habits leading to malocclusion development in childhood." BMC Oral Health, vol. 14, pp. 96, August 2014. https://doi.org/10.1186/1472-6831-14-96.

[87] J. R. Mew, "The postural basis of malocclusion: a philosophical overview." American Journal Orthodontics and Dentofacial Orthopedics, vol. 126, no. 6, pp. 729-738, December 2004. https://doi.org/10.1016/j.ajodo.2003.12.019.

[88] S. G. Blanca, M. L. López, M. A. Rico, and F. Garduño, "Oral clefts: a retrospective study of prevalence and predisposal factors in the state of Mexico." Journal of Oral Science, vol. 50, no. 2, pp. 123-129, June 2008. https://doi.org/10.2334/josnusd .50.123.

[89] I. C. G. Leite, and S. Koifman, "Oral clefts, consanguinity, parental tobacco and alcohol use: a case-control study in Rio de Janeiro. Brazil." Brazilian Oral Research, vol. 23, no. 1, pp. 31-37, January-March 2009. https://doi.org/10.1590/S1806-83242009000100006.

90] I. Zarante, M. A. López, A. Caro, J. C. García-Reyes, and J. C. Ospina, "Impact and risk factor of craniofacial malformations in a Colombian population." International Journal of Pediatric Otorhinolaryngology, 
vol. 73, no. 10, pp. 1434-1437, October 2009. https://doi.org/10.1016/j.ijporl.2009.07.012.

[91] M. Stott-Miller, C. L. Heike, M. Kratz, and J. R. Starr, "Increased risk of orofacial clefts associated with maternal obesity: case-control study and Monte Carlo-based bias analysis." Paediatric and Perinatal Epidemiology, vol. 24, no. 5, pp. 502-512, July 2010. https://doi.org/10.1111/j.1365-3016.2010.01142.x.

[92] K. D. Lebby, F. Tan, and C. P. Brown, "Maternal factors and disparities associated with oral clefts." Ethnicity \& Disease, vol. 20, no. Suppl 1, pp. 146-149, 2010.

[93] J. Suhl, P. A. Romitti, Y. Cao, C. M. Rocheleau, T. L. Burns, K. Conway, et al. "Maternal occupational cadmium exposure and nonsyndromic orofacial clefts." Birth Defects Research, vol. 110, no. 7, pp. 603-609, April 2018. https://doi.org/10.1002/bdr2.1202.

M. Fernanda C. Leal is Associate Professor of Biochemistry at the Faculty of Health Sciences of the University Fernando Pessoa. She holds a PhD in Chemistry from the Faculty of Sciences of the University of Porto and is an Integrated Member of the Centre for Studies in Biomedicine of the Research Unit in Energy, Environment and Health at the University Fernando Pessoa. She has published several books and journal articles on biochemistry and health sciences.

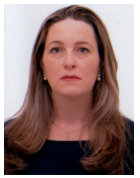

Andreia Lemos holds an Integrated Master in Dental Medicine from the University Fernando Pessoa, Porto, Portugal, and has a specializations in Ortodontics from CIODONTO, Sarandi (Brazil) and in Work Odontology from the Faculty AVM, Rio de Janeiro (Brazil). Has a degree in Odontology from the FIMCA, Porto Velho, Brazil.

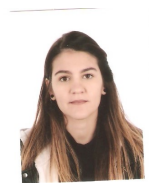

Giselle F. Costa holds an Integrated Master in Dental Medicine from the University Fernando Pessoa, Porto, Portugal, and has a degree in Odontology from the University Santa María, Caracas, Venezuela. Also has several professional courses in Preventive Ortodontics (Dentofacial Orthopedics) from the University Santa María and in Esthetic Odontology from the University San Martín, Colombia.

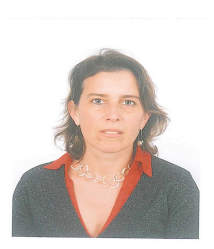

Inês Lopes Cardoso is Associate Professor of Biochemistry and Genetics at the Faculty of Health Sciences of the University Fernando Pessoa. She holds a PhD in Biotechnology from the Superior School of Biotechnology of the Portuguese Catholic University and is an Integrated Member of the Centre for Studies in Biomedicine of the Research Unit in Energy, Environment and Health at the University Fernando Pessoa). She has published several books and journal articles on biochemistry and health sciences. 